\title{
RHINOLOGY
}

Desiderio Passàli · Valerio Damiani

Giulio Cesare Passàli · Francesco Maria Passàli

Luisa Bellussi

\section{Alterations in rhinosinusal homeostasis in a sportive population: our experience with 106 athletes}

Received: 30 October 2003 / Accepted: 30 October 2003 / Published online: 17 December 2003

(C) Springer-Verlag 2003

\begin{abstract}
The aim of the present work was to analyse the alterations of rhino-sinusal physiology in 106 professional athletes (swimmers, skiers, boxers and runners) using objective rhinological methods. Every athlete underwent an accurate anamnesis, a complete objective ORL evaluation, an active anterior rhinomanometry, an acoustic rhinometry and an evaluation of mucociliary transport time (MCTt). Skiers were also submitted to a nasal decongestion test (NDT). In swimmers, the mean MCTt was 27.4 \pm $4.97 \mathrm{~min}$ (normal value: $13 \pm 3 \mathrm{~min} ; P<0.0001$ ). The average MCTt for the skier group was $19.58 \pm 1.92 \mathrm{~min}(P<$ 0.0001 ); the mean value of total basal nasal resistance was $0.37 \pm 0.05 \mathrm{~Pa} / \mathrm{ml}$ per $\mathrm{s}$ (normal value $=0.25 \mathrm{~Pa} / \mathrm{ml}$ per $\mathrm{s}$; $P<0.001)$. After NDT, total nasal resistance was $0.18 \pm$ $0.02 \mathrm{~Pa} / \mathrm{ml}$ per $\mathrm{s}$. In the group of boxers, the total mean nasal resistance was $0.64 \pm 0.05 \mathrm{~Pa} / \mathrm{ml}$ per s $(P<0.001)$; the mean cross-sectional area at the nasal valve level was $0.57 \pm 0.04 \mathrm{~cm}^{2}$ (normal value $=0.55 \pm 0.05 \mathrm{~cm}^{2}$ ) and at the inferior turbinate level $0.83 \pm 0.05 \mathrm{~cm}^{2}$ (normal value $=0.4 \pm$ $\left.0.04 \mathrm{~cm}^{2} ; P<0.001\right)$; the TMC average time was $27.35 \pm$ $2.21 \mathrm{~min}(P<0.0001)$. Finally, for the runners, the mean MCT time was $20.56 \pm 2.35 \mathrm{~min}(P<0.001)$. Knowing the alterations of the physiological nasal respiration is of extreme importance to develop a correct and timely therapeutic approach to be able to restore rhino-sinusal homeostasis. Athletes, in fact, need the earliest therapeutic aid in order to avoid the interference of prolonged rhino-sinusal alterations with their performance and also to avoid a more serious clinical situation concerning the inferior airways.
\end{abstract}

D. Passàli (四 · V. Damiani · G. C. Passàli · L. Bellussi

Department of Otorhinolaryngology,

University of Sienna Medical School,

V. le Bracci, 53100 Sienna, Italy

Tel.: +39-0577-40035, Fax: +39-0577-47940,

e-mail:passali@unisi.it

F. M. Passàli

Department of Otorhinolaryngology,

University of Genoa Medical School, Genoa, Italy
Keywords Rhinosinusal alterations $\cdot$ Nose $\cdot$ Athletes Sport · Airways

\section{Introduction}

By now, it is universally acknowledged that the only actual physiological respiration is the nasal one. In fact, the role played by the nose is to provide the inferior nasal airways with an adequate quantitative and qualitative area supply by means of ventilation, conditioning and defensive functions. Thus, it allows gaseous pulmonary exchanges. If this assertion is true in for the ordinary population, it becomes even more significant in regard to athletes, whose performances are guaranteed by the regular explication of the physiological nasal functions in proportion to their physical efforts. Physiopathologic alterations of the rhino-sinusal district of an athlete change in relation to the sport played. Specifically, in this context, alterations may have a traumatic, vasculomotor or irritative origin or may have all these origins at the same time. As an example, the airway mucosa of a swimmer, who breathes water-steam, is exposed to the irritating effect of chlorine [1] that causes phlogosis and sub-oedema of mucous membrane [2]. Further components of swimming pool waters are chloramines, chloroform, formaldehyde, acetaldehyde and halogenate hydrocarbons [3]. These components are highly volatile, so they pass easily to the aerosol state, and this, together with the peculiarities in terms of $\mathrm{pH}$, temperature and saline composition of swimming pool water, implies the typical clinical picture of nasal obstruction, sneezing and nasal serosa secretion [4], the latter prevalently caused by the alteration of muco-ciliary transport.

Contrarily, the low temperatures to which a skier is exposed play a fundamental role in stimulating a series of parasympathetic reflexes. In the first stage, these reflexes lead to watery nasal secretion, while in the subsequent stage to a district congestion, which is caused by vasum dilatation of the nasal turbinates [5]. From a clinical point of view, this chain of processes represents the typical symptomatological picture of the so-called "skier's nose", 
which is characterised alternatively by watery rhinorrhoea and nasal obstruction. In general, these symptoms develop after $10 \mathrm{~min}$ of exposition to low temperatures and disappear with similar latency after the exposure.

It is also known that nasal trauma, from which osseocartilaginous fractures may derive, are the principal responsible for boxers' rhinosinusal homeostasis (boxer's nose) [6]. These anatomical alterations imply the increase of nasal resistance values. This fact, associated with the frequent use of local haemostatic medicine, causes a lack in balance of the physiological mechanisms of the nasal mucosa.

Finally, with regards to runners' activities, we know that during physical exercise, nasal resistance decreases significantly because of the adrenergic decongestion of the inferior turbinates [7]. This phenomenon appears immediately after starting sportive activity and reaches its peak after about half an hour, then returns to its normal level 25-30 min after one stops running [8]. In the long term for some subjects, this cyclical repetition of turbinate congestion-decongestion may cause serious alterations of the homeostasis of physiological nasal respiration.

In the light of the above considerations, to the extent of preventing the onset of pathologies of the superior airways that are linked with or are the cause of more serious diseases of the inferior airways (rhinobronchial syndrome, asthma, etc.) $[9,10]$, an early and rigorous diagnostic approach is essential, also in cases of minimal rhino-sinusal district alterations.

The aim of this work is to analyse, using objective rhinological methods, the alterations of rhino-sinusal physiology, observed with regard to four different types of professional athletes, whom we follow for a sufficiently long period.

\section{Materials and methods}

For the present study, we enrolled 106 professional athletes (swimmers, skiers, boxers and runners). Specifically, 35 were swimmers, 26 males and 9 females, with an age range of 18 to 35 years (average: 24 years). Twenty-four subjects, 17 males and 7 females, composed the skiers' group, with an age range of 20 to 36 years (average: 28 years). The sample of boxers was formed by 17 subjects, all males, whose age range was between 22 and 37 years (average: 29 years). The last group was formed by 30 athletes ( 19 males and 11 females), chosen among competitive runners who specialised in middle distances $(1,500-5,000 \mathrm{~m})$, their ages ranging between 18 and 36 years (average: 30 years).

Every athlete was submitted to an accurate anamnesis and a complete objective ORL evaluation (eventually integrated with an endoscopy of the rhino-sinusal district), to an active anterior rhinomanometry (AAR), which was executed using the computerised Menfis Rhino System, and to an acoustic rhinometry (AR), which was performed by using the rhino-meter Stimotron Rhinolack 1000 .

In addition, we evaluated every athlete's nasal mucociliary transport through the determination of the time occurred with a coloured marker (vegetal charcoal and saccharin at 3\%), which was placed on the inferior turbinate head to reach the oropharynx [11].

Finally, the skiers were submitted to a nasal decongestion test (DNT) so that after the intranasal nebulisation of a vasoconstrictor (two puffs per naris, repeated twice, at 5-min intervals), we repeated RAA and RA tests.
The statistical analysis of the experimental data was made using the Student's $t$-test.

\section{Results}

Tables 1, 2, 3, 4, and 5 summarize the most significant data among those we collected from the four groups of athletes. Specifically, there was only one rhinologic parameter, pertaining to the group of swimmers, which exceeded the normal range of the adult population: it was the MCT time. In fact, the average MCTt that we calculated in this group is equal to $27.4 \pm 4.97 \mathrm{~min}$, while the common average value of the ordinary population is $13 \pm 3 \mathrm{~min}(P<0.0001)$. In addition, ten of the observed data went over the boundary value by $30 \mathrm{~min}$ (Table 1 ).

The average MCTt for the skiers' group was equal to $19.58 \pm 1.92 \mathrm{~min}$ (versus $13 \pm 3 \mathrm{~min}$ for the general population; $P<0.0001$ ). Instead, the mean value of the total basal

Table 1 Mucociliary transport time in 35 swimmers

\begin{tabular}{|c|c|}
\hline $\begin{array}{l}\text { Swimmer } \\
\text { no. }\end{array}$ & $\begin{array}{l}\text { Mucociliary } \\
\text { transport time } \\
(\mathrm{min})\end{array}$ \\
\hline 1 & 25 \\
\hline 2 & 23 \\
\hline 3 & 21 \\
\hline 4 & 30 \\
\hline 5 & 33 \\
\hline 6 & 24 \\
\hline 7 & 25 \\
\hline 8 & 40 \\
\hline 9 & 28 \\
\hline 10 & 22 \\
\hline 11 & 31 \\
\hline 12 & 35 \\
\hline 13 & 30 \\
\hline 14 & 24 \\
\hline 15 & 27 \\
\hline 16 & 22 \\
\hline 17 & 22 \\
\hline 18 & 33 \\
\hline 19 & 28 \\
\hline 20 & 26 \\
\hline 21 & 21 \\
\hline 22 & 32 \\
\hline 23 & 24 \\
\hline 24 & 31 \\
\hline 25 & 30 \\
\hline 26 & 25 \\
\hline 27 & 33 \\
\hline 28 & 22 \\
\hline 29 & 28 \\
\hline 30 & 31 \\
\hline 31 & 21 \\
\hline 32 & 27 \\
\hline 33 & 30 \\
\hline 34 & 24 \\
\hline 35 & 31 \\
\hline Mean \pm SD & $27.4 \pm 4.94$ \\
\hline
\end{tabular}


Table 2 Nasal resistance, nasal areas and mucociliary transport time in 24 skiers. Basal values

\begin{tabular}{|c|c|c|c|c|}
\hline \multirow[t]{2}{*}{ Skier no. } & \multirow{2}{*}{$\begin{array}{l}\text { Total nasal } \\
\text { resistance } \\
(\mathrm{Pa} / \mathrm{ml} \text { per } \mathrm{s})\end{array}$} & \multirow{2}{*}{$\begin{array}{l}\text { Nasal } \\
\text { Nasal } \\
\text { valve } \\
\left(\mathrm{cm}^{2}\right)\end{array}$} & \multirow{2}{*}{$\begin{array}{l}\text { Areas } \\
\text { Middle } \\
\text { turbinate } \\
\left(\mathrm{cm}^{2}\right)\end{array}$} & \multirow{2}{*}{$\begin{array}{l}\text { MCTt } \\
\text { (Min) }\end{array}$} \\
\hline & & & & \\
\hline 1 & 0.38 & 0.75 & 0.98 & 18 \\
\hline 2 & 0.35 & 0.77 & 0.94 & 20 \\
\hline 3 & 0.50 & 0.74 & 0.99 & 17 \\
\hline 4 & 0.44 & 0.72 & 1.01 & 21 \\
\hline 5 & 0.31 & 0.77 & 0.97 & 23 \\
\hline 6 & 0.35 & 0.78 & 0.95 & 18 \\
\hline 7 & 0.39 & 0.70 & 0.96 & 17 \\
\hline 8 & 0.37 & 0.80 & 0.99 & 22 \\
\hline 9 & 0.36 & 0.75 & 0.98 & 21 \\
\hline 10 & 0.40 & 0.76 & 0.96 & 20 \\
\hline 11 & 0.34 & 0.73 & 0.97 & 19 \\
\hline 12 & 0.35 & 0.73 & 0.95 & 19 \\
\hline 13 & 0.38 & 0.75 & 0.99 & 23 \\
\hline 14 & 0.36 & 0.77 & 0.96 & 18 \\
\hline 15 & 0.39 & 0.78 & 0.98 & 20 \\
\hline 16 & 0.35 & 0.73 & 0.94 & 19 \\
\hline 17 & 0.31 & 0.74 & 0.97 & 18 \\
\hline 18 & 0.4 & 0.77 & 0.95 & 19 \\
\hline 19 & 0.37 & 0.75 & 1 & 21 \\
\hline 20 & 0.39 & 0.73 & 0.97 & 16 \\
\hline 21 & 0.37 & 0.79 & 0.98 & 22 \\
\hline 22 & 0.38 & 0.71 & 0.94 & 18 \\
\hline 23 & 0.35 & 0.77 & 0.96 & 21 \\
\hline 24 & 0.37 & 0.76 & 0.95 & 20 \\
\hline Mean \pm SD & $0.37 \pm 0.05$ & $0.75 \pm 0.02$ & $0.96 \pm 0.02$ & $19.58 \pm 1.92$ \\
\hline
\end{tabular}

nasal resistance was $0.37 \pm 0.05 \mathrm{~Pa} / \mathrm{ml}$ per s (normal value $=0.25 \mathrm{~Pa} / \mathrm{ml}$ per $\mathrm{s} ; P<0.001)$.

Finally, the mean value of cross-sectional areas at the nasal valve level and of the inferior turbinate at basal conditions were, respectively, $0.75 \pm 0.02 \mathrm{~cm}^{2}$ (normal value $\left.=0.55 \pm 0.05 \mathrm{~cm}^{2}\right)$ and $0.96 \pm 0.02 \mathrm{~cm}^{2}($ normal value $=0.48 \pm$ $0.04 \mathrm{~cm}^{2} ; P<0.001$; Table 2).

After NDT, total nasal resistance was $0.18 \pm 0.02 \mathrm{~Pa} / \mathrm{ml}$ per s; on the other hand, the areas of the sections at the nasal valve level and of the inferior turbinate were $0.75 \pm$ $0.02 \mathrm{~cm}^{2}$, but those of the inferior turbinate were $1.44 \pm$ $0.04 \mathrm{~cm}^{2}$ (Table 3), thus indicating a positive statistical significance for this test $(P<0.001)$.

In the boxers' group, the total mean nasal resistance was $0.64 \pm 0.05 \mathrm{~Pa} / \mathrm{ml}$ per s (normal value $=0.25 \mathrm{~Pa} / \mathrm{ml}$ per $\mathrm{s} ; P<0.001)$. The values of the areas of traverses sections for the nasal valve were $0.57 \pm 0.04 \mathrm{~cm}^{2}$ (normal value $=0.55 \pm$ $\left.0.05 \mathrm{~cm}^{2}\right)$ and for the inferior turbinate $0.83 \pm 0.05 \mathrm{~cm}^{2}$ (normal value $=0.4 \pm 0.04 \mathrm{~cm}^{2} ; P<0.001$ ). Finally, the TMC average time was $27.35 \pm 2.21 \mathrm{~min}$ (normal value: $13 \pm 3 \mathrm{~min}$; $P<0.0001$; Table 4).

Finally, in regards to the runners' group (specialised in middle distances), the mean value of the MCT times, compared with the normal level of rhinomanometric and acoustic rhinometric values, was equal to $20.56 \pm 2.35 \mathrm{~min}$ (versus $13 \pm 3$ min of the general population; $P<0.001$; Table 5).
Table 3 Nasal resistance and nasal areas in 24 skiers after pharmacological decongestion

\begin{tabular}{|c|c|c|c|}
\hline \multirow[t]{2}{*}{ Skier no. } & \multirow{2}{*}{ 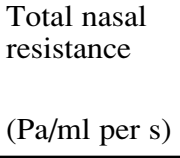 } & Nasal & Areas \\
\hline & & $\begin{array}{l}\text { Nasal } \\
\text { valve } \\
\left(\mathrm{cm}^{2}\right)\end{array}$ & $\begin{array}{l}\text { Middle } \\
\text { turbinate } \\
\left(\mathrm{cm}^{2}\right)\end{array}$ \\
\hline 1 & 0.21 & 0.75 & 1.48 \\
\hline 2 & 0.15 & 0.77 & 1.35 \\
\hline 3 & 0.20 & 0.74 & 1.44 \\
\hline 4 & 0.22 & 0.72 & 1.50 \\
\hline 5 & 0.24 & 0.77 & 1.40 \\
\hline 6 & 0.15 & 0.78 & 1.46 \\
\hline 7 & 0.18 & 0.70 & 1.44 \\
\hline 8 & 0.17 & 0.80 & 1.48 \\
\hline 9 & 0.16 & 0.75 & 1.52 \\
\hline 10 & 0.20 & 0.76 & 1.45 \\
\hline 11 & 0.18 & 0.73 & 1.47 \\
\hline 12 & 0.17 & 0.73 & 1.50 \\
\hline 13 & 0.16 & 0.75 & 1.44 \\
\hline 14 & 0.19 & 0.77 & 1.49 \\
\hline 15 & 0.21 & 0.78 & 1.41 \\
\hline 16 & 0.17 & 0.73 & 1.47 \\
\hline 17 & 0.20 & 0.74 & 1.50 \\
\hline 18 & 0.18 & 0.77 & 1.39 \\
\hline 19 & 0.16 & 0.75 & 1.40 \\
\hline 20 & 0.15 & 0.73 & 1.46 \\
\hline 21 & 0.22 & 0.79 & 1.43 \\
\hline 22 & 0.19 & 0.71 & 1.48 \\
\hline 23 & 0.18 & 0.77 & 1.41 \\
\hline 24 & 0.21 & 0.76 & 1.39 \\
\hline Mean \pm SD & $0.18 \pm 0.02$ & $0.75 \pm 0.02$ & $1.44 \pm 0.04$ \\
\hline
\end{tabular}

Table 4 Nasal resistance, nasal areas and mucociliary transport time in 17 boxers

\begin{tabular}{lllll}
\hline $\begin{array}{l}\text { Boxers } \\
\text { no. }\end{array}$ & $\begin{array}{l}\text { Total nasal } \\
\text { resistance }\end{array}$ & $\begin{array}{l}\text { Nasal } \\
\text { Nasal } \\
\text { valve } \\
\left(\mathrm{cm}^{2}\right)\end{array}$ & $\begin{array}{l}\text { Areas } \\
\text { Middle } \\
\text { turbinate } \\
\left(\mathrm{cm}^{2}\right)\end{array}$ & MCTt \\
$(\mathrm{Ma} / \mathrm{ml}$ per $\mathrm{s})$
\end{tabular}


Table 5 Mucociliary transport time in 30 runners

\begin{tabular}{ll}
\hline $\begin{array}{l}\text { Runner } \\
\text { no. }\end{array}$ & $\begin{array}{l}\text { Mucociliary } \\
\text { transport time } \\
(\text { min })\end{array}$ \\
\hline 1 & 18 \\
2 & 23 \\
3 & 17 \\
4 & 18 \\
5 & 22 \\
6 & 20 \\
7 & 23 \\
8 & 21 \\
9 & 20 \\
10 & 22 \\
11 & 19 \\
12 & 17 \\
13 & 20 \\
14 & 19 \\
15 & 21 \\
16 & 22 \\
17 & 23 \\
18 & 20 \\
19 & 19 \\
20 & 18 \\
21 & 21 \\
22 & 26 \\
23 & 24 \\
24 & 18 \\
25 & 25 \\
26 & 19 \\
27 & 18 \\
28 & 21 \\
29 & 20 \\
30 & \\
Mean \pm SD & $20.56 \pm 2.35$ \\
\hline &
\end{tabular}

\section{Discussion}

On the basis of the critical analysis derived from the results of this research, it is our opinion that there are several interesting elements to elucidate. Namely, the MCTt value of the 35 swimmers increased constantly, reaching values that exceeded $30 \mathrm{~min}$ in ten athletes. This chronic alteration of MCT predisposes swimmers to the onset of serious pathologies such as rhino-sinusitis, rhino-otitis and asthma. In addition, divers may be subject to barotraumatic rhino-sinusitis, which is caused by the continuous and sudden pressure modifications in the rhino-sinusal area.

Concerning the sample of skiers, all of the parameters for objective nasal functionality differed in relation to each tested athlete $(P<0.001)$. In particular, the MCT time increased significantly $(P<0.0001)$. Nevertheless, nasal resistance and cross-sectional areas returned to the normal value range after pharmacological nasal decongestion (NDT). NDT is a test whose specific aim is to distinguish between functional nasal stenosis (which probably can be solved by medical therapy) and mechanical obstructions (which need a surgical approach). NDT positivity, in relation to every skier in the sample, quite unquestionably suggests that these athletes' type of rhinopathy has a vasomotor origin and is characterised by rhinorrhoeaea and nasal congestion. In addition, prolonged exposure to cold may affect oral respiration and aria, the air being neither warmed nor humidified when it arrives in the inferior airways, causing broncho-constriction and thus compromising athletic performance.

The serious anatomic nasal alterations of boxers are responsible for the significant increase of nasal resistance $(P<0.001)$ and reduction of traverse nasal sections. This alteration of physiologic nasal dynamics implies that it is not possible to maintain the balance between nasal and pulmonary respiratory function under stress, and this, obviously, causes diminished athletic performance.

As regards slack facial textures (cutis and mucosa), the damn may be caused by repeated traumatism and continuous haemostasis [12]. Permanent deformation of the nasal pyramid, together with an altered trophism of the mucosa, modifies athletic performance because of the aerial flow reduction of nasal cavities and exposes the athlete to phlogistic pathologies that are principally linked to mucociliary dysfunction with post-traumatic oedema (in fact, TMC time increased for each patient in our study) and to glandular hypersecretion and rhinorrhoea.

It is now known that during physical activity, especially if the latter is protracted, nasal resistance significantly decreases as a consequence of inferior turbinate congestion; this depends on the capacitance vasum constriction because of the release of adrenergic mediator [13]. The persistence of these alterations may cause hypohydration and dryness of rhinosinusal mucosa, thickening of secretion followed by the alteration of mucociliary transport mechanisms and, as a rebound effect, an increase in nasal secretions.

The last effect to be discussed is the clinical situation known as "athlete's nose", which predisposes the subjects to the development of rhinosinusal infections and to recurrent epistaxis. In this context, the results obtained by this last sample of athletes are extremely interesting. In fact, the TMC time of the 30 competitive runners, specialised in middle distances, increased steadily at an average value of $20.56 \pm 2.35$ minutes; this datum is a further clinical confirmation of the physiopathologic mechanisms mentioned above.

Knowing the alterations of the physiological nasal respiration that can arise in athletes and especially in professional competitors, it is of extreme importance to develop a correct and timely therapeutic approach in order to restore rhino-sinusal homeostasis. This group of patients, in fact, needs the earliest therapeutic aid in order to avoid the interference of prolonged rhinosinusal alterations with their athletic performance and also to avoid the development of a more serious clinical situation concerning the inferior airways $[14,15]$.

On the bases of our results, it follows that the therapies should vary with the situation: sometimes, a medical approach is necessary, while at other times, a surgical one. 
The approach depends also on the age of the patient and his or her athletic plans for the future. For example, if the patient is still engaged in athletic competition, the surgery has the goal to revive nasal patency in the best way possible, even to the detriment of other aspects, for example the aesthetic one. However, for subjects who plan to end their athletic career, the surgerical approach may replace the nasal septum to the extent that it can also restore nasal aesthetics. Therefore, we can affirm that if an early diagnostic intervention and a rigorous therapeutic approach are essential for the ordinary population, they became an indispensable need for the specific subjects of our sample.

\section{References}

1. Potts J (1996) Factors associated with respiratory problems in swimmers. Sport Med 21:256-261

2. Brobnik F, Frexia A, Casan P, Sanchis J, Guardino X (1996) Assessment of chlorine exposure in swimmers during training. Med Sci Sport Exerc 28:271-274

3. Aggazzotti G, Fantuzzi G, Righi E, Tartoni P, Cassinandri T, Predieri G (1993) Chloroform in alveolar air of individuals attending indoor swimming pools. Arch Envir Health 48:250-254

4. Benninger MS (1994) Nasal mucociliary transport after exposure to swimming pool water. Am J Rhinol 8:207-212
5. Silvers WS (1991) The skier's nose: a model of cold-induced rhinorrea. Ann Allergy 67:32-36

6. Croce G, Croce A (1987) Nasal trauma in boxers: pathogenesis and treatment. Acta Otorhinolaryngol Ital 7:185-194

7. Olson LG, Strohl KP (1987) The response of the nasal airway to exercise. Am Rev Respir Dis 135:356-360

8. Forsyth RD, Cole P, Shephard RJ (1983) Exercise and nasal patency. J Appl Physiol Respirat Environ Exerc Physiol 55: 860-867

9. Slavin RG (1994) Sinopulmonary relationships. Am J Otolaryngol 15:18-25

10. Varghese BT, Murthy PSN, Rajan RB (2000) Clinico-pathological correlation between allergic rhinitis and asthma. J Laryngol Otol 114:354-358

11. Passàli D, Bellussi L, Bianchini Ciampoli M, De Seta E (1984) Our experience in nasal mucociliary transport time determination. Acta Otolaryngol (Stockh) 97:319-322

12. Lavorgna G, Russo A, Ambrosio A, Alterio F, Dell'Acquila A (1995) I traumi dello scheletro nasale nella pratica pugilistica. Minerva Chir 50:895-899

13. Benninger MS, Sarpa RJ, Ansari T, Ward J (1992) Nasal patency, aerobic capacity and athletic performance. Otolaryngol Head Neck Surg 107:101-109

14. Ferrara A, Di Girolamo S, Passali D (1994) Rhinobronchial syndrome. Acta Otorhinolaryngol Ital 14 [Suppl 43]:47-55

15. Samolinski B, Szczesnowicz-Dabrowska P (2002) Relationship between inflammation of upper and lower respiratory airways. Otolaryngol Pol 56:49-55 